\title{
DNA damage and mutagenesis induced by procarbazine in $\lambda$ lacZ transgenic mice: Evidence that bone marrow mutations do not arise primarily through miscoding by $O^{6}$-methylguanine
}

\author{
Vassiliki Pletsa $^{1}$, Christos Valavanis ${ }^{1}$, Joost H.M.van \\ Delft $^{2}$, Marie-José S.T.Steenwinkel ${ }^{2}$ and \\ Soterios A.Kyrtopoulos ${ }^{1,3}$ \\ ${ }^{1}$ Laboratory of Chemical Carcinogenesis, Institute of Biological Research \\ and Biotechnology, National Hellenic Research Foundation, 48 Vassileos \\ Constantinou Ave, Athens 11635, Greece and ${ }^{2}$ TNO Nutrition and Food \\ Research, Institute, PO Box 360, 3700 AJ Zeist, Utrechtseweg 48, \\ 3704 HE Zeist, The Netherlands \\ ${ }^{3}$ To whom correspondence should be addressed
}

The DNA damaging and mutagenic activities of procarbazine, a methylating drug employed in cancer chemotherapy and suspected of causing therapy-related leukaemia, were investigated in the liver and bone marrow of $\lambda$ lacZ transgenic mice (Muta ${ }^{\mathrm{TM}}$ Mouse). The drug was administered using two different protocols, a 'high-dose' one involving 5 daily doses of $200 \mathrm{mg} / \mathrm{kg}$, expected to cause depletion of the repair enzyme $O^{6}$-alkylguanine-DNA alkyltransferase (AGT) and thus favour the selective accumulation of the premutagenic lesion $O^{6}$-methylguanine $\left(O^{6}\right.$-meG) relative to other adducts, and a 'low-dose' one involving 10 daily doses of $20 \mathrm{mg} / \mathrm{kg}$ procarbazine. Substantial accumulation of $O^{6}$-meG was observed in both tissues examined $6 \mathrm{~h}$ after the end of the 'high-dose' treatment, with the liver accumulating somewhat higher levels than the bone marrow $(28.0 \pm 1.8 \mathrm{fmol} / \mu \mathrm{g}$ DNA and $18.5 \pm 1.1 \mathrm{fmol} / \mu \mathrm{g}$ DNA respectively). However, significant increases in mutant frequency 10 days after the end of treatment were observed only in the bone marrow, reaching a 16-fold increase over background following the $5 \times 200 \mathrm{mg} / \mathrm{kg}$ treatment. Sequence analysis of the mutations induced after this treatment revealed a mixed spectrum, in which $\mathbf{G : C} \rightarrow \mathbf{A}: T$ transitions (characteristic of $O^{6}$-meG miscoding) were only a secondary feature: Among 20 mutants analysed, only six such mutations were found, including three at CpG sites, which might have arisen from deamination of 5-methylcytosine. The other mutations observed included $1 \mathrm{~A}: \mathrm{T} \rightarrow \mathrm{G}: \mathrm{C}$ transition, five transversions (one $\mathrm{G}: \mathrm{C} \rightarrow \mathrm{T}: \mathrm{A}$, one double G:C $\rightarrow$ C:G, two A:T $\rightarrow$ T:A, one A:T $\rightarrow C: G)$, five deletions and three insertions. The mechanistic and clinical significance of these findings is discussed.

\section{Introduction}

Procarbazine [ $N$-isopropyl- $\alpha$-(2-methylhydrazino)- $p$-toluamide hydrochloride] is a cytostatic drug used in the treatment of a number of human cancers, including Hodgkin's lymphoma where, in the form of combination treatments such as MOPP (a combination of procarbazine and mechlorethamine, vincristine and prednisone), it has made a particularly important contribu-

\footnotetext{
*Abbreviations: ANLL, acute non-lymphocytic leukaemia; AGT, $O^{6}$-alkylguanine-DNA alkyltransferase; $O^{6}$-meG, $O^{6}$-methylguanine; NT, not tumorigenic; pfu, plaque forming units; $O^{6}$-meG, $O^{6}$-methylguanine; MOPP, mechlorethamine-vincristine-prednisone-procarbazine.
}

tion to the remarkable progress achieved in terms of long-term survival of patients $(1,2)$. However, this success has been complicated by the appearance, during the 10 years following successful chemotherapy, of an $\sim 5-10 \%$ increased risk of acute non-lymphocytic leukaemia (ANLL*), as well as other types of cancer $(3,4)$. Although procarbazine is not the only potentially carcinogenic component of MOPP, its well recognized genotoxicity $(5,6)$, together with evidence from follow-up studies of ex-Hodgkin's lymphoma patients (7), cause concern that it may make a significant contribution to the mechanism of MOPP carcinogenesis. Procarbazine is mutagenic, clastogenic and teratogenic in a wide range of test systems of varying complexity and a wide-spectrum carcinogen in rodents and monkeys, causing tumours of the haemopoietic system, the mammary gland, the lung and the nervous system (8).

In vivo procarbazine undergoes a complex series of metabolic changes that result in the generation of a number of chemically reactive species, including methylating agents and free radicals (9). The major circulating metabolite in the serum of animals or humans treated with procarbazine is methylazoxyprocarbazine, a relatively stable intermediate that can spontaneously give rise to a methylating species, probably the methyldiazonium ion $\left[\mathrm{CH}_{3} \mathrm{~N}_{2}\right]^{+}$. The main type of macromolecular damage known to be produced by procarbazine is DNA methylation, with the liver accumulating the highest amounts of such damage, followed closely by the bone marrow and lymph nodes, two tissues of interest as targets for the carcinogenic and chemotherapeutic action of the drug $(10,11)$. Procarbazine produces in DNA $O^{6}$-methylguanine $\left(O^{6}-\mathrm{meG}\right)$ and $N 7$-methylguanine at a ratio of $\sim 0.12$, typical of an $\mathrm{S}_{\mathrm{N}} 1$-type methylating agent and similar to that caused by such powerful mutagens and carcinogens as methylnitrosourea and dimethylnitrosamine (10). It is therefore strongly suspected that DNA methylation plays a major role in the mutagenic and carcinogenic activity of this drug. Of the various DNA lesions induced by methylating mutagens and carcinogens, $O^{6}-\mathrm{meG}$ has particularly important biological activity. It is a directly miscoding lesion, causing $\mathrm{G}: \mathrm{C} \rightarrow \mathrm{A}: \mathrm{T}$ mutations, and is believed to be the cause of the frequent discovery of this type of mutation in activated oncogenes found in animal tumours induced by methylating agents $(12,13)$. In a study of mammary carcinogenesis induced in rats by procarbazine and methylnitrosourea, Fong et al. (14) found that the yield of tumours by the two carcinogens correlated approximately with the production in mammary gland DNA of $O^{6}-\mathrm{meG}$. In a subsequent study (15), a correlation was reported between accumulation of $O^{6}$ $\mathrm{meG}$ and sensitivity to procarbazine-induced tumorigenesis in different tissues, including the mammary gland, the lymph nodes and the thymus. These results support the hypothesis that $O^{6}$-meG plays a significant role in the mechanism of procarbazine carcinogenesis in experimental animals.

Comparative studies of the formation of $O^{6}-\mathrm{meG}$ in rats and in Hodgkin's lymphoma patients have shown that human susceptibility to procarbazine-induced $O^{6}$-meG accumulation 
is similar to that of the rat (16), suggesting that this lesion may play a similar mutagenic role in humans treated with procarbazine as it does in the rat. Evidence compatible with an etiological role of $O^{6}-\mathrm{meG}$ in the induction of ANLL after MOPP chemotherapy was produced by Sagher et al. (17) who found that MOPP-treated individuals who went on to develop ANLL had lower lymphocyte levels of $O^{6}$-alkylguanine-DNA alkyltransferase (AGT), the enzyme responsible for repair of $O^{6}$-meG, than similarly treated individuals who did not develop ANLL. This observation implied that individuals with low levels of AGT may be at higher risk of procarbazine-induced carcinogenesis by accumulating higher amounts of $O^{6}$-meG during MOPP chemotherapy. Further support for this suggestion was obtained through the direct measurement of the formation of $O^{6}$-meG in blood leukocyte DNA of procarbazinetreated patients (18) and the demonstration that individuals with low pre-treatment AGT levels accumulate high amounts of $O^{6}-\mathrm{meG}$, an observation also observed in patients treated with another methylating drug, dacarbazine $(19,20)$.

Summarizing, data on the quantitative accumulation of $O^{6}$ meG provide some evidence compatible with this lesion being important in procarbazine-induced carcinogenesis in experimental animals and MOPP-induced ANLL in humans. However, this evidence is far from conclusive. A key event in the initiation of chemical carcinogenesis is the conversion of pre-mutagenic DNA damage into a mutation in the target tissues through the replication of damage-containing cells. The advent of the technology of transgenic rodents with transgenes, which can serve as readily observable targets for chemical mutagens, provides a new way for investigating the ability of carcinogens to induce mutations in tissues susceptible to their carcinogenic effects. Furthermore, the examination of the specific types of sequence changes caused by a mutagen provides a powerful tool for the assessment of the role of specific DNA lesions in the induction of mutagenesis, which are under the full complexity of metabolic and repair pathways that operate under in vivo conditions. Procarbazine has been reported to induce a significant increase in mutant frequency in the bone marrow of $\lambda$ lacZ mice (Muta ${ }^{\mathrm{TM}}$ Mice) 7 days after the completion of treatment consisting of five daily doses of $200 \mathrm{mg} / \mathrm{kg}$ (21). However, no information on the relationship between mutagenesis and DNA adduct induction in any tissue of such treated animals was given in this report. In the present study we have examined the accumulation of $O^{6}-\mathrm{meG}$ as well as the frequency and types of mutations in the liver and bone marrow of $\lambda$ lacZ transgenic mice treated with procarbazine. We find that, even though after five daily treatments with $200 \mathrm{mg} / \mathrm{kg}$ procarbazine, there were slightly lower amounts of $O^{6}$-meG accumulated in the bone marrow than the liver: a strong mutagenic response was induced only in the former tissue, and the spectrum of induced mutations was not dominated by the characteristic fingerprint of $O^{6}-\mathrm{meG}(\mathrm{G}: \mathrm{C} \rightarrow \mathrm{A}: \mathrm{T}$ transitions).

\section{Materials and methods}

\section{Chemicals}

Samples of procarbazine hydrochloride were obtained from Hoffman La Roche, Basle and from the Drug Synthesis and Chemistry Branch, Developmental Therapeutics Program, National Cancer Institute, USA. The drug was stored desiccated in an amber bottle at $-20^{\circ} \mathrm{C}$ and dissolved (protected from light) in physiological saline just before use.

Animal treatment

Male $\lambda$ lacZ transgenic mice (Muta ${ }^{\mathrm{TM}}$ Mouse) (16), 9-10 weeks old, purchased from Hazleton, were maintained on normal laboratory chow. Groups of four mice were treated i.p. with multiple doses of procarbazine $(10 \times 20 \mathrm{mg} / \mathrm{kg}$ or $5 \times 200 \mathrm{mg} / \mathrm{kg}$ at $24-\mathrm{h}$ intervals) or with physiological saline only. One animal from each group was killed $4 \mathrm{~h}$ after the last treatment and used for measurement of $O^{6}$-meG in liver and bone marrow DNA, while the remaining three animals were killed 10 days after the last treatment for mutation analysis in the same tissues. Tissues of interest were immediately placed in liquid nitrogen and stored at $-70^{\circ} \mathrm{C}$ until analysis.

Measurement of $\mathrm{O}^{6}$-meG

Following DNA extraction from liver and bone marrow of individual animals by a standard method involving multiple proteinase $\mathrm{K}$ treatments and phenolchloroform extractions, $O^{6}-\mathrm{meG}$ was measured by the competitive repair assay as previously described (22) using E.coli AGT (ada protein). Each DNA sample was analysed in duplicate and duplicate measurements agreed to within $10 \%$ of each other.

Mutagenesis in the $\lambda$ lacZ transgenic mouse

High molecular-weight genomic DNA was isolated from liver and bone marrow as previously described (23), dissolved in $10 \mathrm{mM}$ Tris- $\mathrm{HCl}(\mathrm{pH} 7.5)$ and $4 \mathrm{mM}$ EDTA to a final concentration of $1.5 \mathrm{mg} / \mathrm{ml}$ and stored at $4^{\circ} \mathrm{C}$. A $5 \mu \mathrm{l}$ aliquot of each of the DNA solutions was taken and the $\lambda$ prophages were rescued in vitro using the Giga-Pack II Gold packaging extract (Stratagene, La Jolla, CA). Screening for lacZ $Z^{-}$mutant phages was carried out by using the phenyl- $\beta$-D-galactopyranoside (P-gal)-based positive selection system (24) and all mutants were confirmed on 5-bromo-4-chloro-3-indolyl- $\beta$-D-galactopyranoside (X-gal) plates. Generally $>3 \times 10^{5}$ plaque forming units (pfu) were analysed in each case.

For the sequence-characterization of representative mutants, the location of the mutation in the $\alpha, \beta$ or $\omega$ regions of the lacZ gene was determined using a $\beta$-galactosidase complementation assay as described by Douglas et al. (25). The relevant region was subsequently amplified by PCR and subjected to dideoxy sequencing.

\section{Results}

$O^{6}$-Methylguanine accumulation in liver and bone marrow DNA

Animals were treated with two dosing schedules of procarbazine, one involving five daily doses of $200 \mathrm{mg} / \mathrm{kg}$, anticipated to cause substantial depletion of AGT and thus favour the preferential accumulation of $O^{6}-\mathrm{meG}$, and one involving 10 daily doses of $20 \mathrm{mg} / \mathrm{kg}$, expected to generate relatively low levels of $O^{6}-\mathrm{meG}$. In order to obtain an indication of the adduct levels formed and their tissue distribution, from each group of treated animals one was killed $4 \mathrm{~h}$ after the last treatment and $O^{6}$-meG was measured in liver and bone marrow DNA. The results are shown in Table I, where it can be seen that the high-dose treatment resulted in the accumulation of large amounts of $O^{6}$-meG in both the liver and the bone marrow, the latter tissue accumulating approximately twothirds of the adducts of the liver. Although changes in AGT were not measured, given the pre-treatment levels of AGT in $\lambda$ lacZ transgenic mice $[5.1 \mathrm{fmol} / \mu \mathrm{g}$ DNA for the liver and 0.7 $\mathrm{fmol} / \mu \mathrm{g}$ DNA for the bone marrow (V.L.Souliotis et al., unpublished results)] it is likely that substantial depletion of this enzyme occurred in both tissues. The death of one of the animals treated with low doses of procarbazine prevented the measurement of the resulting adducts in this case.

\section{Mutant frequency analysis}

The remaining animals per group were killed 10 days after the last treatment and mutant frequency in the lac $\mathrm{Z}$ transgene was determined in the liver and bone marrow. As can be seen in Table I, no statistically significant increase in mutant frequency was observed in the liver after either treatment, although one animal in each case gave a particularly high mutant frequency value. In the bone marrow, a 5-fold increase was observed in both animals treated with $10 \times 20 \mathrm{mg} / \mathrm{kg}$ procarbazine $(P<0.005)$, while a much greater increase occurred in each of the three animals treated with $5 \times 200 \mathrm{mg} /$ 


\begin{tabular}{|c|c|c|c|c|c|c|c|}
\hline \multirow[t]{2}{*}{ Tissue } & \multirow{2}{*}{$\begin{array}{l}\text { Procarbazine } \\
\text { treatment }\end{array}$} & \multicolumn{2}{|c|}{$O^{6}-\mathrm{meG}($ mean $\pm \mathrm{SD})$} & \multirow{2}{*}{$\begin{array}{l}\mathrm{pfu} \times 10^{5} \\
\text { counted }\end{array}$} & \multirow{2}{*}{$\begin{array}{l}\text { Confirmed } \\
\text { mutants }\end{array}$} & \multirow{2}{*}{$\begin{array}{l}\text { Mutant frequency } \\
\left.\text { (per } 10^{6} \mathrm{pfu}\right)\end{array}$} & \multirow{2}{*}{$\begin{array}{l}\text { Mutant frequency } \\
\text { (per } 10^{6} \mathrm{pfu} \text { ) mean (SD) }\end{array}$} \\
\hline & & $\mathrm{fmol} / \mu \mathrm{g}$ DNA & $\mu \mathrm{mol} / \mathrm{molG}$ & & & & \\
\hline \multirow[t]{9}{*}{ Liver } & \multirow[t]{3}{*}{ None } & \multirow[t]{3}{*}{ Not detected } & \multirow[t]{3}{*}{ Not detected } & 5.50 & 30 & 54 & \multirow[t]{3}{*}{$46(10)$} \\
\hline & & & & 6.05 & 30 & 49 & \\
\hline & & & & 13.95 & 49 & 35 & \\
\hline & \multirow[t]{3}{*}{$10 \times 20 \mathrm{mg} / \mathrm{kg}$} & \multirow[t]{3}{*}{ Not done ${ }^{b}$} & \multirow[t]{3}{*}{ Not done ${ }^{b}$} & 3.88 & 12 & 31 & \multirow[t]{3}{*}{$83(66)$} \\
\hline & & & & 5.70 & 35 & 61 & \\
\hline & & & & 2.03 & 32 & 157 & \\
\hline & \multirow[t]{3}{*}{$5 \times 200 \mathrm{mg} / \mathrm{kg}$} & \multirow[t]{3}{*}{$28.0 \pm 1.8$} & \multirow[t]{3}{*}{$44.8 \pm 2.8$} & - & - & $-^{\mathrm{c}}$ & \multirow[t]{3}{*}{$103(53)$} \\
\hline & & & & 2.95 & 15 & 50 & \\
\hline & & & & 1.34 & 21 & 156 & \\
\hline \multirow[t]{9}{*}{ Bone marrow } & \multirow[t]{3}{*}{ None } & \multirow[t]{3}{*}{ Not detected } & \multirow[t]{3}{*}{ Not detected } & 3.70 & 20 & 54 & \multirow[t]{3}{*}{$41(22)$} \\
\hline & & & & 3.00 & 16 & 53 & \\
\hline & & & & 16.26 & 24 & 15 & \\
\hline & \multirow[t]{3}{*}{$10 \times 20 \mathrm{mg} / \mathrm{kg}$} & \multirow[t]{3}{*}{ not done ${ }^{b}$} & \multirow[t]{3}{*}{ Not done ${ }^{b}$} & - & - & $-^{\mathrm{c}}$ & \multirow[t]{3}{*}{$203(7)$} \\
\hline & & & & 3.60 & 75 & 210 & \\
\hline & & & & 2.22 & 44 & 196 & \\
\hline & \multirow[t]{3}{*}{$5 \times 200 \mathrm{mg} / \mathrm{kg}$} & \multirow[t]{3}{*}{$18.5 \pm 1.1$} & \multirow[t]{3}{*}{$29.6 \pm 2.5$} & 4.99 & 350 & 700 & \multirow[t]{3}{*}{$650(76)$} \\
\hline & & & & 3.50 & 240 & 686 & \\
\hline & & & & 1.90 & 107 & 562 & \\
\hline
\end{tabular}

${ }^{\mathrm{a}}$ Measured $6 \mathrm{~h}$ and 10 days, respectively, after completion of treatment.

${ }^{\mathrm{b}}$ Not measured due to death of animal.

${ }^{\mathrm{c}}$ Not measured because of poor quality of extracted DNA.

$\mathrm{kg}$ procarbazine. The 16-fold average increase from $41 \pm 22$ mutants $/ 10^{6}$ pfu to $650 \pm 76$ mutants $/ 10^{6}$ pfu $(P<0.0005)$ agrees well with the report of Myhr (21) who found a mutant frequency of 772 mutants $/ 10^{6}$ pfu 7 days after completion of a similar treatment.

Sequence characterization of procarbazine-induced mutations In view of the relatively small increase in bone marrow mutant frequency observed after the low-dose treatment, sequence characterization of the resulting mutations was impractical. On the other hand, the 16-fold increase observed after the highdose treatment meant that almost all of these mutants were probably induced by procarbazine and that their sequence analysis could provide useful information for the assessment of the DNA lesions responsible for their induction. Therefore 20 mutants from this group were randomly selected and sequenced (Tables II and III). The DNA sequence changes found were all different from each other, indicating that the mutants were derived from independent mutation events. All possible types of single base substitutions were observed, as well as base insertions and deletions. The most frequent mutations were transitions (7/20), dominated by $\mathrm{G}: \mathrm{C} \rightarrow \mathrm{A}: \mathrm{T}$ changes (six out of the seven transitions, including three mutations at $\mathrm{CpG}$ dinucleotides). Five transversions were observed (including a $\mathrm{GC} \rightarrow \mathrm{CG}$ double substitution), as well as five deletions (four of which involved G:C pairs) and three insertions. This mutation spectrum is in broad agreement with that reported by Myhr et al. following the analysis of a much smaller number of mutants (21).

\section{Discussion}

In an effort to investigate the mechanism of procarbazine mutagenesis and to obtain an indication of the role of $O^{6}-\mathrm{meG}$ in it, we examined adduct and mutation induction in the liver and bone marrow of $\lambda$ lac $Z$ transgenic mice after treatment with multiple doses of this agent. $O^{6}$-Methylguanine was measured $6 \mathrm{~h}$ after the last of five or 10 daily treatments. Previous studies with a number of methylating agents, including
Table II. Bone marrow lacZ mutants in mice treated with procarbazine $(5 \times 200 \mathrm{mg} / \mathrm{kg})$ and killed 10 days after last treatment

\begin{tabular}{|c|c|c|c|c|}
\hline Mutant no. & lacZ region & Mutation & Position & Sequence \\
\hline 1 & $\alpha$ & $\mathrm{C}: \mathrm{G} \rightarrow \mathrm{T}: \mathrm{A}$ & 127 & CTGGCGGTAA \\
\hline 2 & $\alpha$ & $\mathrm{G}: \mathrm{C} \rightarrow \mathrm{T}: \mathrm{A}$ & 229 & GCCGGA \\
\hline 3 & $\beta$ & $\mathrm{C}: \mathrm{G} \rightarrow \mathrm{A}: \mathrm{T}$ & 487 & CGGGㅡㅡGCTG \\
\hline 4 & $\beta$ & Insertion $\mathrm{C}$ & $507-508$ & CCAG $\underline{C} G A C A$ \\
\hline 5 & $\beta$ & $\mathrm{C}: \mathrm{G} \rightarrow \mathrm{T}: \mathrm{A}$ & 619 & 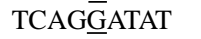 \\
\hline 6 & $\beta$ & $\mathrm{A}: \mathrm{T} \rightarrow \mathrm{C}: \mathrm{G}$ & 621 & AGGATATGT \\
\hline 7 & $\beta$ & Deletion $\mathrm{T}$ & 641 & GGCAT̄TTTC \\
\hline 8 & $\beta$ & Deletion $\mathrm{C}$ & 777 & ACTAㅡㅡТАC \\
\hline 9 & $\beta$ & $\mathrm{A}: \mathrm{T} \rightarrow \mathrm{T}: \mathrm{A}$ & 785 & CGGGT̄AACA \\
\hline 10 & $\beta$ & Deletion $\mathrm{C}$ & 830 & GGCAㅡㅡㄷGCG \\
\hline 11 & $\beta$ & $\mathrm{C}: \mathrm{G} \rightarrow \mathrm{T}: \mathrm{A}$ & 928 & CGCC高AAAT \\
\hline 12 & $\beta$ & $\mathrm{G}: \mathrm{C} \rightarrow \mathrm{A}: \mathrm{T}$ & 1164 & AGAAC̄AACT \\
\hline 13 & $\beta$ & Insertion $\underline{\mathrm{TG}}$ & $1164-1165$ & AGAAT $\underline{T}$ GAAC \\
\hline 14 & $\beta$ & $\mathrm{A}: \mathrm{T} \rightarrow \mathrm{G}: \overline{\mathrm{C}}$ & 1210 & GCTG $\underline{\overline{T G} G T A}$ \\
\hline 15 & $\beta$ & $\mathrm{CG}_{1} \rightarrow \mathrm{GC}$ & 1217,1218 & TACA $\overline{\bar{C}}$ GCTGT \\
\hline 16 & $\beta$ & $\mathrm{A}: \mathrm{T} \rightarrow \mathrm{T}: \mathrm{A}$ & 1242 & TGTATGTGG \\
\hline 17 & $\beta$ & Deletion $\mathrm{G}$ & 1480 & TGAA $\underline{\text { GGCGG }}$ \\
\hline 18 & $\beta$ & Insertion $\mathrm{C}$ & $1631-1632$ & AATA드GCC \\
\hline 19 & $\beta$ & $\mathrm{C}: \mathrm{G} \rightarrow \mathrm{T}: \mathrm{A}$ & 1652 & AACA菷CTT \\
\hline 20 & $\omega$ & Deletion G & 2034 & ATGTĒGCTC \\
\hline
\end{tabular}

procarbazine, have shown that repeated daily treatments result in a steady accumulation of $O^{6}-\mathrm{meG}$, which is reflected in the adduct levels present at the end of the treatment period $(11,26,27)$. Furthermore, $O^{6}-\mathrm{meG}$ appears to have similar lifetimes in the liver and the bone marrow of the rat following AGT-depleting doses of procarbazine or MNU, suggesting that the relative adduct levels observed at $4 \mathrm{~h}$ post-treatment are representative of the overall adduct load of the two tissues (11). Finally, the above series of studies has demonstrated a relatively small animal-to-animal variation in the observed adduct levels, typically involving a standard deviation $<20 \%$. Thus, although adduct measurements in the present study were obtained at only one time-point and in single animals, and therefore do not provide a basis for quantitative adduct- 
Table III. Summary and comparison of spontaneous and procarbazineinduced lacZ mutation spectra in bone marrow

\begin{tabular}{llll}
\hline Type of mutation & $\begin{array}{l}\text { Spontaneous } \\
\text { Myhr } \text { et al. }(21) \\
n=20\end{array}$ & $\begin{array}{l}\text { Procarbazine-induced } \\
\text { Myhr } \text { et al. }(21) \\
n=8\end{array}$ & $\begin{array}{l}\text { This work } \\
n=20\end{array}$ \\
\hline Transitions & 16 & 2 & 7 \\
$\mathrm{G}: \mathrm{C} \rightarrow \mathrm{A}: \mathrm{T}$ & $15\left(14^{\mathrm{a}}\right)$ & 1 & $6\left(3^{\mathrm{a}}\right)$ \\
$\mathrm{A}: \mathrm{T} \rightarrow \mathrm{G}: \mathrm{C}$ & 1 & 1 & 1 \\
Transversions & 2 & 6 & 5 \\
$\mathrm{G}: \mathrm{C} \rightarrow \mathrm{T}: \mathrm{A}$ & 2 & - & 1 \\
$\mathrm{G}: \mathrm{C} \rightarrow \mathrm{C}: \mathrm{G}$ & - & 1 & 1 (double) \\
$\mathrm{A}: \mathrm{T} \rightarrow \mathrm{T}: \mathrm{A}$ & - & 3 & 2 \\
$\mathrm{~A}: \mathrm{T} \rightarrow \mathrm{C}: \mathrm{G}$ & - & 2 & 1 \\
Deletions & 2 & - & 5 \\
Insertions & - & - & 3 \\
\hline
\end{tabular}

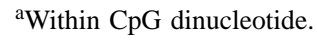

mutagenesis comparisons, they provide an adequate indication of the relative magnitude of DNA damage that occurred in the two tissues examined.

Despite the fact that the liver accumulated the highest levels of $O^{6}$-meG (up to $28.0 \pm 1.8 \mathrm{fmol} / \mu \mathrm{g} \mathrm{DNA}$, corresponding to $\sim 53000$ residues of $O^{6}$-meG per $10^{6}$ lacZ transgenes, after the high-dose treatment), no statistically significant increase in liver mutagenesis could be detected with either dosing regimen. It has been suggested that the induction of toxicity-related liver cell proliferation may be a necessary prerequisite for mutagenesis (28). Although no specific information on the hepatotoxicity of procarbazine is available, the liver does not appear to be among the main targets of the toxicity of this compound, which are the gonads, the lung and the haematopoietic system (8). It thus seems possible that the low rate of liver cell proliferation after procarbazine treatment did not favour the efficient conversion of these adducts into mutations.

In contrast to what was observed with the liver, a doserelated increase in bone marrow mutagenesis was induced by both procarbazine treatments employed. Thus, despite the accumulation after the high dose treatment of $30 \%$ lower amounts of $O^{6}-\mathrm{meG}$ in the bone marrow than the liver $(18.5 \pm 1.1 \mathrm{fmol} / \mu \mathrm{g}$ DNA, corresponding to 35000 adduct residues per $10^{6}$ transgenes), a 16-fold increase of mutagenesis over background was observed in the former tissue. The much greater susceptibility of the bone marrow to procarbazine mutagenesis is probably due in part to its greater basal rate of cell proliferation. In addition, the bone marrow is a major target for the acute toxicity of procarbazine $(8,29,30)$, which is expected to lead to restorative cell proliferation and favour mutation fixation, thus accounting for the susceptibility of the bone marrow to procarbazine mutagenesis. A number of studies (reviewed in reference 8) have shown that the haematopoietic system is also a major target of procarbazine carcinogenesis in the mouse. Interestingly, the same appears to be true in the monkey (31), in contrast to the rat where induction of leukaemia was relatively rare (8).

In addition to the rate of cell proliferation being an important factor that determines the relative tissue susceptibility to procarbazine mutagenesis, it is also possible that the accumulation of $O^{6}-\mathrm{meG}$ is not a good measure of the critical premutagenic damage induced by procarbazine, i.e. that miscoding by this lesion is not the primary mechanism of mutagenesis by this agent. Such an explanation would be compatible with the mutation spectrum observed (Table III), in which G:C $\rightarrow \mathrm{A}: \mathrm{T}$ transitions (the fingerprint of $O^{6}$-meG miscoding) constitute only $30 \%$ of the total. For comparison, it is noted that AGTdepleting doses of the methylating agents $N$-nitrosodimethylamine or $N$-methyl- $N$-nitrosourea gave rise to $80 \%$ and $95 \%$ $\mathrm{G}: \mathrm{C} \rightarrow \mathrm{A}: \mathrm{T}$ transitions in the liver and the spleen, respectively, of lacI transgenic mice $(28,32)$. As three of the six $\mathrm{G}: \mathrm{C} \rightarrow \mathrm{A}: \mathrm{T}$ mutations induced by procarbazine were at $\mathrm{CpG}$ sites, it is possible that some or all of these might have arisen by deamination of 5-methylcytosine, thus decreasing the proportion of mutations likely to have derived from direct $O^{6}-\mathrm{meG}$ miscoding even further. On the other hand, two of the remaining $\mathrm{G}: \mathrm{C} \rightarrow \mathrm{A}: \mathrm{T}$ mutations were at the $3^{\prime}-\mathrm{G}$ of pu-G dinucleotides (a site known to be favoured for $O^{6}-\mathrm{meG}$ mutagenesis) and can probably be attributed to this lesion. Although $O^{6}-\mathrm{meG}$ was the only adduct measured in the present study, it is expected that other DNA adducts (particularly N7-methylguanine and N3-methyladenine) were also produced in substantial amounts during the multiple treatments. Furthermore, procarbazine is known to undergo a complex pattern of metabolism, which in addition to the production of methylating intermediate(s), also leads to the formation of free radical species (9). If genotoxic species other than a methylating agent are also formed during the metabolism of procarbazine, they might well undergo substantial reaction with guanine (the most nucleophilic base in DNA) and give rise to some of the G-centred sequence changes observed. If alternative pathways of procarbazine metabolism result in the addition to DNA of the bulky side chain attached to the second hydrazine nitrogen, the resulting lesions might, for example, account for the frequent observation of frameshifts at or next to $\mathrm{G}$ (seven out of eight insertions or deletions), including four instances of frameshifts at GG dinucleotides, sites known to favour polymerase slippage (33).

A mixed mutation spectrum with a high proportion of frameshifts, especially those associated with polymerase slippage, is characteristically observed in mutants derived from cells deficient in mismatch repair $(34,35)$. Methylating agents such as $N$-methyl- $N$-nitrosourea are well known to readily cause mutational inactivation of mismatch repair genes in mammalian cells, giving rise to mutants that, in addition to being hypermutable, are methylation tolerant and thus would have a growth advantage in a background of toxic methylation insult (36). The mixed mutation spectrum and the relatively high frequency of frameshifts observed in this study (Table III) would thus be compatible with the possibility of an additional pathway of procarbazine mutagenesis involving the inactivation of mismatch repair and subsequent generation of procarbazineresistant cells prone to replication errors. While compatible with our observations and in line with known mutagenic properties of methylating agents, this hypothesis would need to be tested by specially designed experiments. An alternative possibility to consider is that the repetitive cycles of abortive mismatch repair that take place on the strand opposite $O^{6}$ meG (36), believed to be the main basis of the cytotoxicity of this lesion, may give rise to DNA rearrangements in cells that survive this process.

Mutations in the ras oncogene have been detected in blood leukocytes of patients who had undergone cytotoxic therapy for lymphoma, which probably included procarbazine (38). Of the nine mutations found, seven were transversions (five $\mathrm{G}: \mathrm{C} \rightarrow \mathrm{T}: \mathrm{A}$, one $\mathrm{G}: \mathrm{C} \rightarrow \mathrm{C}: \mathrm{G}$, one $\mathrm{A}: \mathrm{T} \rightarrow \mathrm{C}: \mathrm{G}$ and two $\mathrm{A}: \mathrm{T} \rightarrow \mathrm{G}: \mathrm{C}$ transitions). Although the small number of mutations characterized and the uncertain nature of the administered chemotherapy 
do not permit any definitive conclusions, it is evident that this mutation spectrum does not resemble the one observed in the present study. On the other hand, the absence of ras gene $\mathrm{G}: \mathrm{C} \rightarrow \mathrm{A}: \mathrm{T}$ mutations is in concordance with the low proportion of such mutations in the present study and supports the suggestion that direct miscoding by $O^{6}-\mathrm{meG}$ may not be the main source of procarbazine-induced mutations. If confirmed by further studies, this suggestion might have important implications regarding the possibility of modification of chemotherapeutic protocols involving procarbazine with the aim of enhancing their therapeutic efficacy. Since there is evidence that $O^{6}$-meG contributes substantially to the toxicity of procarbazine $(39,40)$, in principle it would be possible to enhance this drug's cytostatic efficacy through the depletion of AGT, along lines similar to those currently the subject of extensive experimental studies and clinical trials with nitrosourea-based drugs (41). However, in contrast to the latter drugs that bring about their mutagenic effects primarily via DNA cross-links, rather than $O^{6}$-alkylguanine-type lesions, any enhancement of procarbazine-induced $O^{6}$-meG accumulation would carry with it the undesirable risk of a substantial increase in mutagenicity. If, on the other hand, $O^{6}-\mathrm{meG}$ plays only a minor role in procarbazine mutagenesis, as implied by the results reported here, such risks may be smaller than until now anticipated. This would open the way to protocol modifications that might be particularly valuable in the treatment of brain tumours, where procarbazine-mediated chemotherapy has not met with the success that it has in the case of Hodgkin's lymphoma.

In conclusion, the data reported here indicate that the mouse bone marrow is highly susceptible to procarbazine mutagenesis and that mutations induced may not be primarily derived from direct miscoding by $O^{6}-\mathrm{meG}$. The molecular mechanism of the observed mutagenesis, and whether the same mechanism determines mutagenesis in genes involved in procarbazine carcinogenesis in man, are important questions that remain to be elucidated.

\section{Acknowledgements}

The technical assistance of Irene Kolonti is gratefully acknowledged. This work was supported by a grant by the European Commission (contract no. EV5V-CT91-0012).

\section{References}

1.DeVita,V.T. (1981) The consequences of the chemotherapy of Hodgkin's disease: the 10th David A. Karnofsky Memorial Lecture. Cancer, 47, 1-13.

2. Bonadonna,G., Balagussa,P. and Santoro,A. (1985) Prognosis of bulky Hodgkin's disease treated with chemotherapy alone or combined with radiotherapy. Cancer Surv., 4, 439-458.

3.Kaldor,J.M., Day,N.E. and Hemminki,K. (1988) Quantifying the carcinogenicity of antineoplastic drugs. Eur. J. Cancer Clin. Oncol., 24, 703-711.

4.Levine,E.G. and Bloomfield,C.D. (1992) Leukemias and myelodysplastic syndromes secondary to drug, radiation and environmental exposure. Semin. Oncol., 19, 47-84.

5.Lee,I.P. and Dixon,R.L. (1978) Mutagenicity, carcinogenicity and teratogenicity of procarbazine. Mutat. Res., 55, 1-14.

6. Waters,D. and Stack,H.F. (1988) The short-term test activity profile for procarbazine hydrochloride. Mutagenesis, 3, 89-94.

7. Pedersen-Bjergaard,J., Specht,L., Olesen-Larsen,S., Ersboll,J., Struck,J., Hansen,M.M., Hansen,H.H. and Hissen,N.I. (1987) Risk of therapy-related leukaemia and preleukaemia after Hodgkin's disease: Relation to age, cumulative dose of alkylating agents, and time from chemotherapy. Lancet, ii, 83-88.

8. International Agency for Research on Cancer (1981) Procarbazine hydrochloride. IARC Monographs on the Evaluation of Carcinogenic Risks to Humans, no. 26. IARC, Lyon, France.

9. Prough,R.A. and Tweedie,D.J. (1987) Procarbazine. In Powis,G. and
Prough,R.A. (eds) Metabolism and Action of Anti-cancer Drugs. Taylor and Francis, London, New York, Philadelphia, pp. 29-47.

10. Wiestler,O., Kleihues,P., Rice,J. and Imankovic,S. (1984) DNA methylation in maternal, fetal and neonatal rat tissues following perinatal administration of procarbazine. J. Cancer Res. Clin. Oncol., 108, 56-59.

11. Valavanis,C., Souliotis,V.L. and Kyrtopoulos,S.A. (1994) Differential effects of procarbazine and methylnitrosourea on the accumulation of $O^{6}$ methylguanine and the depletion and recovery of $O^{6}$-alkylguanine-DNA alkyltransferase in rat tissues. Carcinogenesis, 15, 1681-1688.

12. Newcomb,E.W., Bayona,W. and Pisharody,S. (1995) $N$-methylnitrosoureainduced Ki-ras codon 12 mutations: early events in mouse thymic lymphomas. Mol. Carcinogenesis., 13, 89-95.

13. Devereux,T.R., Belinsky,S.A., Maronpot,R.R., White,C.M., Hegi,M.E., Patel,A.C., Foley,J.F., Greenwell,A. and Anderson,M.W. (1993) Comparison of pulmonary $O^{6}$-methylguanine-DNA adduct levels and Kiras activation in lung tumours from resistant and susceptible mouse strains. Mol. Carcinogenesis., 8, 177-185.

14.Fong,L.Y.Y., Jensen,D.E. and Magee,P.N. (1990) DNA methyl-adduct dosimetry and $O^{6}$-alkylguanine-DNA alkyltransferase activity determinations in rat mammary carcinogenesis by procarbazine and methylnitrosourea. Carcinogenesis, 11, 411-417.

15. Fong,L.Y.Y., Bevill,R.F., Thurmon,J.C. and Magee,P.N. (1992) DNA adduct dosimetry and DNA repair in rats and pigs given repeated doses of procarbazine under conditions of carcinogenicity and human cancer chemotherapy respectively. Carcinogenesis, 13, 2153-2159.

16. Souliotis,V.L., Valavanis,C., Boussiotis,V.A., Pangalis,G.A. and Kyrtopoulos,S.A. (1994) Comparative dosimetry of $O^{6}$-methylguanine in humans and rodents treated with procarbazine Carcinogenesis, 15, $1675-1680$.

17. Sagher,D., Karrison,T., Schwartz,J.L., Larson,R., Meier,P. and Strauss,B. (1988) Low $O^{6}$-alkylguanine-DNA alkyltransferase activity in the peripheral blood lymphocytes of patients with therapy-related acute nonlymphocytic leukemia. Cancer Res., 48, 3084-3089.

18. Souliotis,V.L., Kaila,S., Boussiotis,V.A., Pangalis,G.A. and Kyrtopoulos,S.A. (1990) Accumulation of $O^{6}$-methylguanine in human blood leukocyte DNA during exposure to procarbazine and its relationships with dose and repair. Cancer Res., 50, 2759-2764.

19.Lee,S.M., O'Connor,P.J., Thatcher,N., Crowther,D., Margison,G.P. and Cooper,D.P. (1994) Relationships between the formation of $O^{6}$ methyldeoxyguanosine by 1-p-carboxyl-3,3-dimethylphenyltriazene in DNA and $O^{6}$-alkylguanine-DNA alkyltransferase in human peripheral leukocytes. Cancer Res., 54, 4072-4046.

20.Philip,P.A, Souliotis,V.L., Harris,A.L., Salisbury,A., Tates,A.D., Mitchell,K., van Delft,J.H.M., Ganesan,T. and Kyrtopoulos,S.A. (1996) Methyl DNA adducts, DNA repair, and hypoxanthine-guanine phosphoribosyl transferase mutations in peripheral white blood cells from patients with malignant melanoma treated with dacarbazine and hydroxyurea. Clin. Cancer Res., 2, 303-310.

21. Myhr,B.C. (1991) Validation studies with MutaTMMouse: A transgenic mouse model for detecting mutations in vivo. Environ. Mol. Mutagenesis, 18, 308-315.

22. Souliotis, V.L. and Kyrtopoulos,S.A. (1989) A novel sensitive for $O^{6}$ methyl and $O^{6}$-ethyl guanine in DNA, based on repair by the enzyme $O^{6}$ alkylguanine-DNA alkyltransferase in competition with an oligonucleotide containing $O^{6}$-methylguanine. Cancer Res., 49, 6996-7001.

23. Gossen,J.A., de Leeuw,W.J.F., Tan,C.H.T., Zwarthoff,E.C., Berends,F., Lohman,P.H.M., Knook,D.L. and Vijg,J. (1989) Efficient rescue of integrated shuttle vectors from transgenic mice: A model for studying mutations in vivo. Proc. Natl Acad. Sci. USA, 86, 7971-7975.

24. Mientjes,E.J., van Delft,J.H.M., op't Hof,B.M., Gossen,J.A., Vijg,J., Lohman,P.H.M. and Baan,R.A. (1994) An improved selection method for $\lambda$ lacZ-phages based on galactose sensitivity. Transgenic Res., 3, 67.

25. Douglas,G.R., Gingerich,J.D., Gossen,J.A. and Bartlett,S.A. (1994) Sequence spectra of spontaneous lacZ gene mutations in transgenic mouse somatic and germline tissues. Mutagenesis, 9, 451-458.

26. Souliotis,V.L., Valavanis,C., Boussiotis,V.A., Pangalis,G.A. and Kyrtopoulos,S.A. (1996) Comparative study of the formation and repair of $O^{6}$-methylguanine in humans and rodents treated with dacarbazine. Carcinogenesis, 17, 725-732.

27. Souliotis,V.L., Chhabra,S., Anderson,L.M. and Kyrtopoulos,S.A. (1995) Dosimetry of $O^{6}$-methylguanine in rat DNA after low-dose, chronic exposure to $N$-nitrosodimethylamine (NDMA). Implications for the mechanism of NDMA hepatocarcinogenesis. Carcinogenesis, 16, 23812387.

28. Mirsalis,J.C., Provost,G.S., Matthews,C.D., Hamner,R.T., Schindler,J.E., O'Loughlin,K.G., Macgregor,J.T. and Short,J.M. (1993) Induction of hepatic mutations in lacI transgenic mice. Mutagenesis, 8, 265-271. 


\section{V.Pletsa et al.}

29. Romagna,F., Matsumura,H., Watanabe,M., Kato,T., Shirasu,Y., Ohmori,K., Yamada,H. and Sasaki,Y.F. (1992) Micronucleus evaluation in peripheral blood reticulocytes of mice treated with procarbazine hydrochloride or mitomycin C. Mutat. Res., 278, 197-204.

30. Romagna,F. and Schneider,B.M. (1990) Comparison of single/multipledose protocols using triethylenemelamine and procarbazine hydrochloride for the mouse bone marrow micronucleus test. Mutat. Res., 234, 169-178.

31. Thorgeirsson,U.P., Dalgard,D.W., Reeves,J. and Adamson,R.H. (1994) Tumor incidence in a chemical carcinogenesis study of nonhuman primates. Regul. Toxicol. Pharmacol., 19, 130-151.

32. Provost,G.S., Kretz,P.L., Hamner,R.T., Matthews,C.D., Rogers,B.J., Lundberg,K.S., Dycaico,M.J. and Short,J.M. (1993) Transgenic systems for in vivo mutation analysis. Mutat. Res., 288, 133-149.

33. Streisinger,G. and Owen,J. (1985) Mechanisms of spontaneous and induced frameshift mutation in bacteriophage T4. Genetics, 109, 633-659.

34. Malkhosyan,S., McCarty,A., Sawai,H. and Perucho,M. (1996) Differences in the spectrum of spontaneous mutations in the hprt gene between tumor cells of the microsatellite mutator phenotype. Mutat. Res., 316, 249-259.

35. Hess,P., Aquilina,G., Dogliotti,E. and Bignami,M. (1994) Spontaneous mutations at aprt locus in a mammalian cell line defective in mismatch recognition. Somat. Cell Mol. Genet., 20, 409-421.

36. Karran,P. and Bignami,M. (1994) DNA damage tolerance, mismatch repair and genome instability. Bioassays, 16, 833-839.

37. Carter,G., Hughes,D.C., Clark,R.E., McCormick,F., Jacobs,A., Whittaker,J.A. and Padua,R.A. Ras mutations in patients following cytotoxic therapy for lymphoma. Oncogene, 5, 411-416, 1990.

38. Schold,S.C., Brent,T.P., Vonhofe,E., Friedman,H.S., Mitra,S., Bigner,D.D., Swenberg,J.A. and Kleihues,P. (1989) $O^{6}$-Alkylguanine-DNA alkyltransferase and sensitivity to procarbazine in human brain-tumour xenografts. J. Neurosurg., 70, 573-577.

39. Bobola,M.S., Blank,A., Berger,M.S. and Silber,J.R. (1995) Contribution of $O^{6}$-methylguanine-DNA methyltransferase to monofunctional alkylatingagent resistance in human brain tumor-derived cell lines. Mol. Carcinogenesis, 13, 70-80.

40. Gerson,S.L. and Willson,J.K. (1995) $O^{6}$-alkylguanine-DNA alkyltransferase. A target for the modulation of drug resistance. Hematol. Oncol. Clin. N. Am., 9, 431-450.

41.Pegg,A.E., Dolan,M.E. and Moschel,R.C. (1995) Structure, function and inhibition of $O^{6}$-alkylguanine-DNA alkyltransferase. Prog. Nucl. Acid. Res. Mol. Biol., 51, 167-223.

Received on June 3, 1997; revised on July 23, 1997; accepted on August 4, 1997 